\title{
Teaching Reform Studies of the Course "Semiconductor Physics" Under the Mode of Compound New Engineering Talent Training
}

\author{
Xia Wu, Wanling Deng", Zhi Luo, Junkai Huang \\ Department of Electronic Engineering, Jinan University, Guangzhou 510630, China \\ ${ }^{*}$ Corresponding author. Email: dwanL@126.com
}

\begin{abstract}
Semiconductor physics is the basis of semiconductor science and integrated circuits. And this course is one of the main basic courses for undergraduates majoring in electronic engineering. Under the background of new engineering course construction and talent training, in this paper, we introduce a teaching platform with multi-dimensional structure for "Semiconductor Physics", which consists of multi-dimensional structure of theory teaching, virtual labs and simulations, and multi-dimensional experimental teaching subsystem. The teaching achievements in the course "Semiconductor Physics" are awarded by our university. As a consequence, the teaching mode proposed in this paper can be served as a guidance for the education in electrical engineering and information science field.
\end{abstract}

Keywords: Teaching reform studies, semiconductor physics, teaching model with multi-dimensional structure, compound new engineering talent training

\section{INTRODUCTION}

In order to proactively cope with the scientific and technological revolutions and industrial changes, a series of national strategies such as "Made in China 2025" are proposed [1]. Since February 2017, the Ministry of Education has actively promoted the construction of new engineering disciplines, and has moved towards the main theme of talent training, which builds a new path for engineering education reform. "New Engineering" emphasizes the practicability, interdisciplinarity and comprehensiveness of the disciplines, with particular emphasis on the close integration of new information technologies such as network communications, artificial intelligence, and software engineering with traditional industrial technologies. In terms of talent training, in the future, emerging industries and new economic societies will need compound "New Engineering" talents with more practical and innovative capabilities and international competitiveness [2]. They can use their knowledge to solve existing problems, and also have the ability to learn new knowledge and technology to solve new problems emerging in the future. They will play a leading role in future technology and industry.

The course of "Semiconductor Physics" is a basic course for undergraduates majoring in electronic engineering. On the one hand, the rapid developments of technologies and industries are emerging, such as artificial intelligence, the internet of things, new energy, semiconductor and integrated circuit industries. China has achieved important developments in semiconductor and integrated circuit industry. In order to increase the self-sufficiency rate of domestic chips as soon as possible, it is critical to obtain independent intellectual property rights in high-end integrated circuit (IC) chips and their related technologies. On the other hand, the development of the semiconductor and IC industries is closely related to the engineering education in colleges and universities. Therefore, it is significant to train new engineering talents in semiconductor and integrated circuits under the background of new economy developments.

\section{BASIC THEORY IN TEACHING REFORM}

In traditional teaching, classroom teaching is mainly based on theoretical contents, and it is difficult to stimulate students' sustained learning interest [3]. As the "Semiconductor Physics" course covers semiconductor materials, solid-state physics, quantum mechanics, mathematical analysis, and electronic circuits, it is a comprehensive course that requires students to have a solid basic knowledge of mathematics. At the same time, most of the theoretical contents and concepts of the course are very abstract, as well as the related model characterization and formula derivations such as energy band structure, carrier concentration, heterojunction, etc. In other words, it is hard to understand the course contents without help. In addition, the rapid development of semiconductor physics and its device technology makes it difficult for existing teaching 
materials to cover more and more new knowledges. Moreover, "Semiconductor Physics" courses in most colleges and universities have the corresponding experimental courses. But in these experimental classes, student participation is not active enough.

Based on the above-mentioned teaching status and problems in the course of "Semiconductor Physics", and under the background of "New Engineering", this article studies the teaching reform of this course and cultivation of outstanding engineering talents. In this paper, we propose a teaching platform related to this course as shown in Fig. 1. The details of this multi-dimensional structure teaching platform are described in the following sections.

\subsection{Multi-dimensional Structure of Theory Teaching}

As mentioned earlier, the content of this course covers multiple subject areas such as physics, mathematics, materials science, and electronic science. With the continuous emergence of new knowledge, there is a trend of interdisciplinary, making this course as a research one. Therefore, it requires that teachers cannot just refer to the fixed content of a textbook for teaching, but must continuously update, deepen and extend the teaching contents with the development of science and technology and the teachers' research work [4]. So, we form a multi-dimensional curriculum teaching subsystem.

In the teaching reform of the course contents, it is necessary to highlight the idea of modular integration teaching. Firstly, the "Basic Knowledge" teaching module in the teaching subsystem, provides systematic basic knowledge for the course of "Semiconductor Physics", which plays a key role of further understanding of basic theory. Secondly, the "Comprehensive knowledge" teaching module is a "bond" for students' knowledge extension, the aim of which is to establish a dynamic knowledge framework of semiconductor physics and integrated circuit technology. It integrates the basic knowledge and advanced research progress in the classroom teaching, which enhances interdisciplinary knowledge and application methods for students. Thirdly, the "Expanding Knowledge" teaching module provides "Core Content" and "Extended Content" to highlight the concept of self-learning. It gives space for students at different levels to develop their interests and thinking.

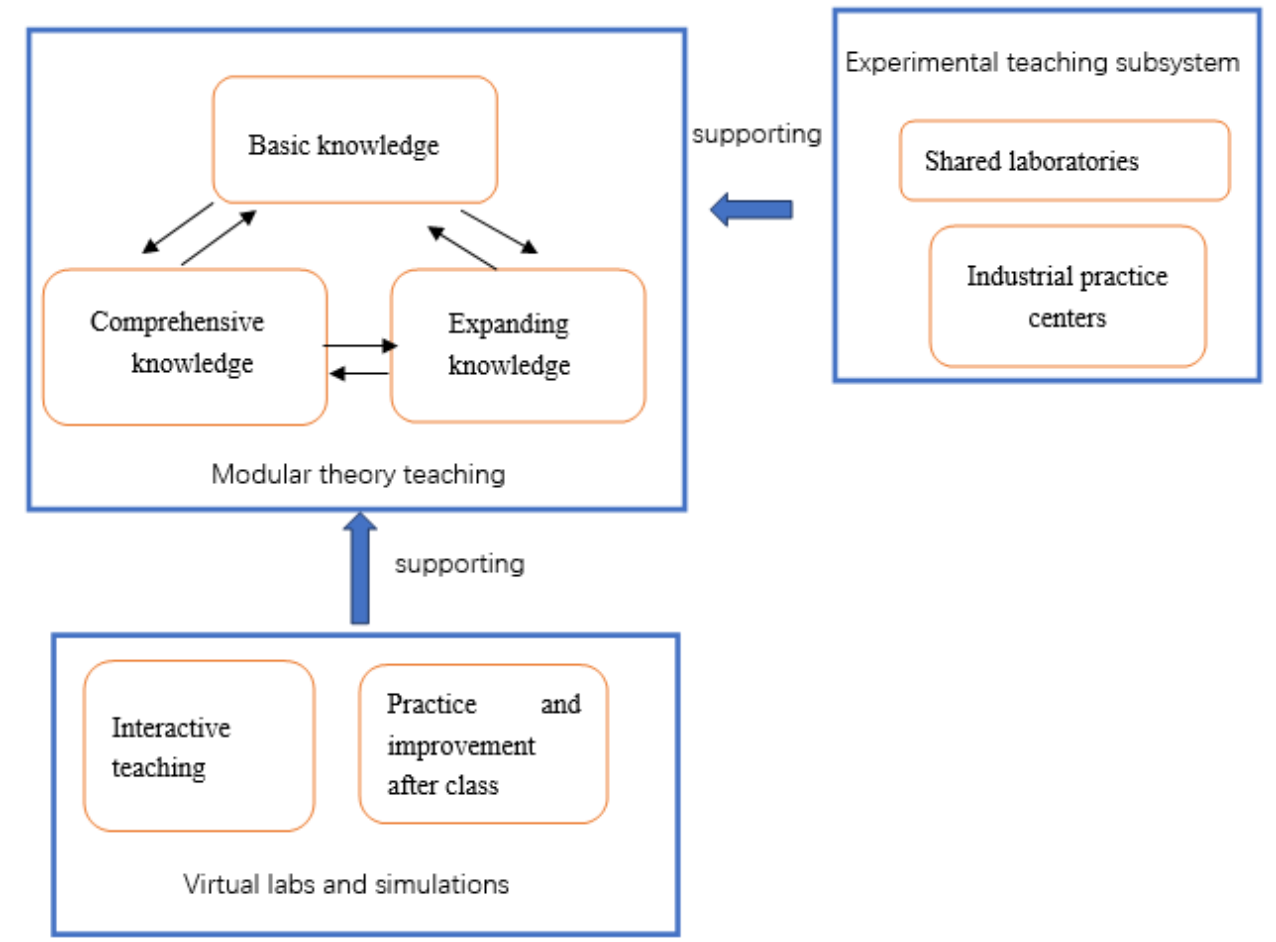

Figure 1 Diagram of the teaching mode with multi-dimensional structure platform 


\subsection{Virtual Labs and Teaching Resource Database}

Virtual labs, i.e., software simulating the real processing, are very convenient for both teachers and students. Software in virtual labs does not involve in the complex experimental processing, but it gives a clear view for the students about the working principle, the physical details inside the devices, the results of application, and so on. In the course of "Semiconductor Physics", we also need to use dynamic simulations and simulation practices of various semiconductor materials and devices to enhance students' further understanding in their working principles and applications. On the Internet or using the cloud-computing technology, students in dorms or anywhere at which they have a computer- or smartphone-like terminal, can enter the virtual labs and do some assignments or research works. Additionally, teachers can manage and design their teaching materials in the database. Students can also share their learning experiences.

Furthermore, the virtual labs make a connection between the academic teaching and the industrial applications. By designing different application scenario modules, it provides a variety of semiconductor materials and other application objects, and uses a virtual simulation environment to allow students to have intuitive and emotional engineering practice cognition.

\subsection{Multi-dimensional Experimental Teaching Subsystem}

As shown in Fig.2, to realize the transformation of engineering knowledge to engineering ability, undergraduates in domestic and foreign universities usually participate in the scientific research activities. There are two main forms: students' participation as research assistants in research groups led by teachers, and student projects proposed by themselves including research projects, engineering design projects, and public service projects, etc. For the research programs, students should apply for research fundings from their schools. Due to the discipline background, the former obviously has the characteristics of "New Engineering". Therefore, with the guidance of teachers and the needs from industry, and aimed at the engineering applications, students can realize the transformation from engineering knowledge to engineering ability.

Facing the requirements of "New Engineering" construction, we integrate and improve the experimental platform for semiconductor devices with the characteristics of sharing and school-enterprise co-construction, which makes a solid foundation for the reform of practical teaching in this course [5]. At the same time, through building a semiconductor material and device application environment in this subsystem, students can be trained for innovative ability based on the industry advanced equipments and hardware conditions [6]

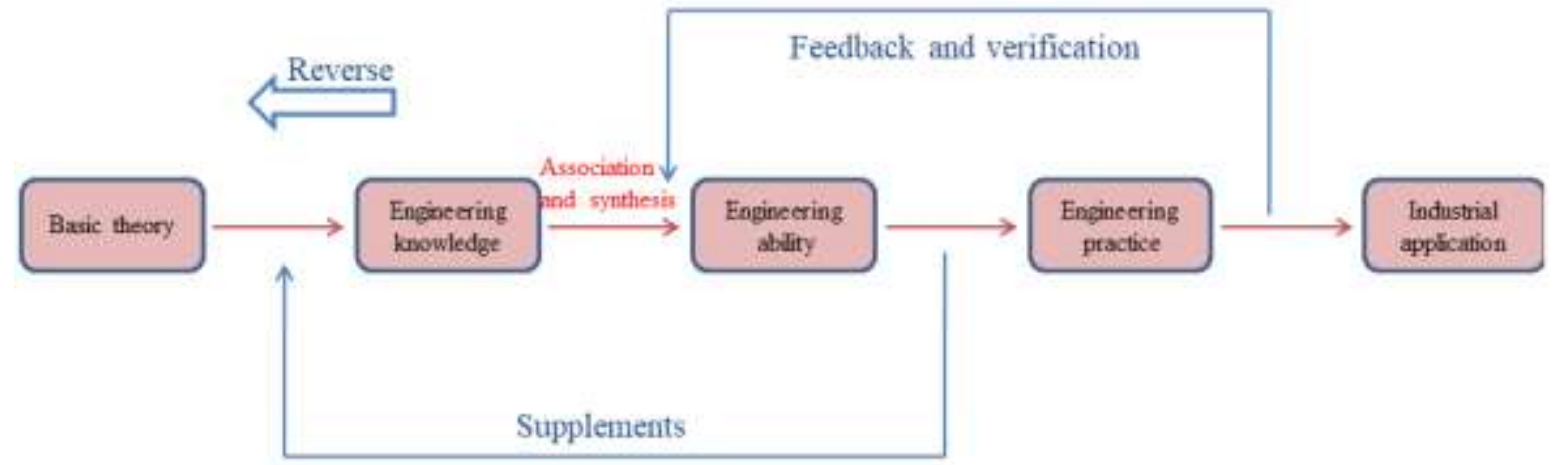

Figure 2 Engineering knowledge in experimental courses

\section{TEACHING ACHIEVEMENTS}

The teaching reform mode of the course "Semiconductor Physics" has been used in Electronic Engineering Department of Jinan University for several years, and we obtained some achievements. Our department has several provincial engineering centers, one of which focuses on micro-nano electronics research and student training. It also has a teaching and research platform that provides products and solutions for enterprises. Over the years, we have developed a variety of core products with new semiconductor and optoelectronic materials and devices.
We also have a industry-university-research alliance, which provides the whole process support for the theory teaching, experimental instruments and equipment, application trying, and test measurements for the practical teaching in semiconductor physics and device courses.

\section{SUMMARY}

"Semiconductor Physics" has a lot of concepts, theories, formulas and abstract physical models, which makes most students not interested in learning. In order to enhance students' initiative and enthusiasm for learning, and improve the teaching quality of "Semiconductor Physics" course, we 
have developed a teaching platform with multi-dimensional structure. It introduces the idea of modular integration teaching method, virtual labs and real-time simulations, and open-labs with hardware and industrial equipment. This teaching mode effectively improves students' learning initiative, engineering ability and passions for the semiconductor industry.

\section{ACKNOWLEDGEMENT}

This research was financially supported by Fund Project of Laboratory Management Committee of Guangdong Higher Education Society, Jinan

University Undergraduate Teaching Team

Building Project, International Science and Technology Cooperation Program of China (No. 2015DFR11050), Applied Science and Technology Research and Development Special Fund Project of Guangdong Province of China (No. 2016B010126004), and External Cooperation Program of Guangdong Province of China (No. 2013B051000060).

\section{REFERENCES}

[1] S. X. Liu, Innovation Design: Made in China 2025, J. Design Management Review, 27 (2016) 52-58.

[2] M. A. Youndt, M. Subramaniam, The influence of intellectual capital on the types of innovative capabilities, The Academy of Management Journal, 48 (2005) 450-463.

[3] R. A. Kusurkar, G. Croiset, C. Ten, T. J. Olle, Twelve tips to stimulate intrinsic motivation in students through autonomy-supportive classroom teaching derived from self-determination theory, J. Medical Teacher, 33 (2011) 978-982.

[4] E. F. Katharine, M. J Annette. Integration what is taught with what is practiced in the nursing curriculum: A multi-dimensional model, Journal of Advanced Nursing, 20 (1994) 687-695.

[5] L. V. Parés, A. Alsina, The transformation of practical teaching focusing on dialogic learning, J. Procedia - Social and Behavioral Sciences, 141 (2014) 5-9.

[6] Y. K. Kuo, T. H. Kuo, L. A. Ho, Enabling innovative ability: knowledge sharing as a mediator, J. Industrial Management \& Data Systems, 114 (2014) 696-710. 